\title{
Community Engagement Through Partnerships: Lessons Learned from a Decade of Full-service Community School Implementation
}

\author{
Monica A. Medina, Gayle Cosby \& Jim Grim
}

To cite this article: Monica A. Medina, Gayle Cosby \& Jim Grim (2019) Community Engagement Through Partnerships: Lessons Learned from a Decade of Full-service Community School Implementation, Journal of Education for Students Placed at Risk (JESPAR), 24:3, 272-287, DOI: 10.1080/10824669.2019.1615923

To link to this article: https://doi.org/10.1080/10824669.2019.1615923

曲 Published online: 14 May 2019.

Submit your article to this journal $2 \pi$

Џ Article views: 39

View Crossmark data ¿ 


\title{
Community Engagement Through Partnerships: Lessons Learned from a Decade of Full-service Community School Implementation
}

\author{
Monica A. Medina, Gayle Cosby, and Jim Grim \\ School of Education, Indiana University-Purdue University Indianapolis
}

\begin{abstract}
Improving performance in an environment often tested by intermingled social problems, including poverty, racial isolation, cultural clashes between teachers and students, and school funding disparities requires authentic, committed family, school, and community partnerships. Using Bryk's (2010) model for effective and improving schools, our study describes challenges and achievements experienced over a decade of implementing the full-service community school (FSCS) reform in two neighborhoods in Indianapolis, Indiana. We also share lessons about funding, collaborative structures and processes, and organizational responses to change. The study has broad implications for both FSCSs and urban schools with comparable demographics that are working to build effective partnerships to address social problems in lasting ways.
\end{abstract}

\section{Introduction}

Challenges facing urban schools and their communities include the seemingly permanent disparities of poverty (Brooks-Gunn \& Duncan, 1997), inadequate school resources (Warren, 2002), lack of highly qualified teachers (Darling-Hammond, 2006), and contemptibly low rates of academic achievement and high school graduation (Wirt et al., 2004). Many school reforms fail to consider the systemic issues affecting students and families, and the complex problems plaguing the urban communities where they live. However, models of school-community collaboration have recently reemerged to address the broader issues faced by struggling urban schools. Full-service community school (FSCS) strategies encourage schools and communities to work together to discuss common problems, increase access to and provision of services, and build social capital among students, families, and communities (e.g., Galindo, Sanders, \& Abel, 2017).

Using Bryk, Sebring, Allensworth, Luppescu, \& Easton (2010) model for effective and improving schools as the main theoretical framework, this case study discusses the challenges and significant achievements experienced in over a decade of planning and implementing a comprehensive community school strategy. The study draws on data from two communities in Indianapolis, Indiana, Near-Westside and MartindaleBrightwood. Both neighborhoods are within the Indianapolis Public School (IPS) district 
and face increasing economic inequity. Twenty to $40 \%$ of residents make $200 \%$ or less of the federal poverty level, are situated in food deserts, and have high academic and social needs, placing students and families in these communities at risk (Riggs et al., 2017). One can quickly create a deficit opinion of these communities, yet they both have a legacy of bringing people together to address social and economic issues. Both communities have also received funding from the U.S. Department of Education to develop and sustain FSCSs.

\section{Full-service community schools and the Indianapolis initiative}

The Coalition for Community Schools defines a FSCS as the hub of its neighborhood, uniting families, educators and community partners to provide all students with topquality academics, enrichment, health and social services, and opportunities to succeed in school and life (Blank et al., 2003). The U.S. Department of Education describes them as "public elementary or secondary schools that collaborate with local educational agencies and community-based organizations, non-profits, and other public or private entities" (Catalog of Federal Domestic Assistance (CFDA), 2018) to improve students' socio-emotional, physical, and academic outcomes. Recent research confirms the FSCS model as a risk-reduction strategy that promotes resilience among children and adolescents (Oakes, et al., 2017; Lubell, 2011).

For over a decade, Indianapolis has sustained one of the nation's most comprehensive FSCS reform initiatives (Grim, Medina, \& Officer, 2011. FSCSs in the IPS district provide support services including tutoring and mentoring, extended-day learning activities, college prep, parent engagement, mental health services, academic enrichment, community-based service learning, health and wellness, basic assistance, and youth development. The goals of these schools are to improve graduation rates, academic achievement, performance on state and national assessments, attendance rates, the overall well-being of students and families, family engagement, and the percentage of families that receive services from nearby community centers (Grim et al., 2011).

\section{Neighborhood sites for full-service community schools in Indianapolis}

Two neighborhoods in Indianapolis have been awarded FSCS grants - Near-Westside and Martindale-Brightwood. Near-Westside has received two separate grants from the U.S. Department of Education, one in 2008 and another in 2015. Additionally, Martindale-Brightwood received a FSCS grant from the U.S. Department of Education in 2010. Both communities also have long histories of working with the school system and anchor organizations in addressing the needs of students and developing the core foundations of FSCSs, educational success, health and wellbeing, and strong instructional programs (Lubell, 2011).

\section{Near-Westside}

With support from a grant from the U.S. Department of Housing and Urban Development, Indiana University-Purdue University Indianapolis (IUPUI) developed a partnership with the Westside Cooperative Organization in October 1998. Together, 
they organized a Community Education Forum to discuss with local residents the potential impact of a court action to overturn the district's longstanding desegregation order, and the closing of Jefferson High School (Jefferson High; names of participating schools are pseudonyms) in 1995. This forum resulted in the establishment of the Westside Education Task Force to respond to the court order to reverse mandatory bussing and to advocate for the reopening of Jefferson High as a FSCS.

Since reopening, Jefferson High has been recognized by the National Association of Secondary School Principals, MetLife Foundation, Annie E. Casey Foundation, KnowledgeWorks Foundation, and Coalition for Community Schools as an exemplary model. Since receiving a second U.S. Department of Education award of \$2.3 million in 2015, Mary Rigg Neighborhood Center, the lead partner in Near-Westside, has expanded the FSCS model to include four nearby feeder elementary schools serving grades K-8; Cesar Chavez (CC) Elementary, Junipero Serra (JS) Elementary, Zora Neale Hurston (ZNH) Elementary and Mahatma Gandhi (MG) Elementary (see Table 1). The new grant is being used to assess the overall impact of the FSCSs on diverse student outcomes (e.g., attendance, achievement, graduation, suspensions). As the community school reform is taken to scale in Near-Westside, its multiple partnerships are the engine fostering continued improvements for students, families, and community members.

\section{Martindale-Brightwood}

The Martindale-Brightwood neighborhoods of Indianapolis were initially founded near the hub of two railroads. In the latter part of the 19th century, the railroad industry was a source of employment in the flourishing area. The neighborhood remained a working-class suburb until the railroad station, which brought so much prosperity to the area, relocated to an outer-ring suburb, leaving people jobless. The area fell into economic depression, which it is still experiencing today (Davila, Nowlin, \& Andres, 2018).

The Martindale-Brightwood Alliance for Educational Success (MBAES) was born of a partnership between IUPUI and IPS. In 2010, the Community Learning Network of IUPUI was awarded 2.5 million dollars in federal funding to initiate a university-assisted community schools model in three ethnically diverse elementary schools in Martindale-Brightwood (see Table 2). A comprehensive implementation plan was developed in partnership with IPS, the Edna Martin Christian Center, Bright House Network, 37 Place, Art With a Heart and other partners based on vital information gathered from principals and school staff, parents, and students. The broad plan was

Table 1. Demographics and academic achievement for participating FSCSs at Near-Westside.

\begin{tabular}{lcccc}
\hline & $\begin{array}{c}\text { Jefferson Community } \\
\text { High School (JCHS) }\end{array}$ & $\begin{array}{c}\text { Cesar Chavez } \\
\text { Elementary (CC) }\end{array}$ & $\begin{array}{c}\text { Zora Neale Hurston } \\
\text { Elementary (ZNH) }\end{array}$ & $\begin{array}{c}\text { Junipero Serra } \\
\text { Elementary (JS) }\end{array}$ \\
\hline Total Enrollment (numbers) & 612 & 658 & 693 & 412 \\
\% White & 25 & 34 & 15 & 46 \\
\% Black & 31 & 13 & 26 & 13 \\
\% Latinx & 38 & 49 & 54 & 31 \\
\% Other Race & 1 & 4 & 6 & 9 \\
\% Free/Red Lunch & 74 & 77 & 78 & 83 \\
\% Passing 17-18 ISTEP* & NA & 24 & 11 & 22 \\
\hline
\end{tabular}

Source: Indiana Department of Education.

Data not available for Mahatma Gandhi (MG) Elementary as this is a charter restart.

*ISTEP, Indiana Statewide Testing for Educational Progress. 
Table 2. Demographics and academic achievement for participating fscss at martindale Brightwood.

\begin{tabular}{lccc}
\hline & $\begin{array}{c}\text { Victoria Woodhull } \\
\text { Elementary (VW) }\end{array}$ & $\begin{array}{c}\text { Fannie Lou } \\
\text { Hamer (FLH) }\end{array}$ & $\begin{array}{c}\text { Alice Paul } \\
\text { Elementary (AP) }\end{array}$ \\
\hline Total Enrollment (numbers) & 166 & 414 & 693 \\
\% White & 3 & 6 & 15 \\
\% Black & 84 & 59 & 25 \\
$\%$ Latinx & 10 & 32 & 54 \\
\% Other Race & 2 & 3 & 6 \\
\% Free/Red Lunch & 83 & 73 & 78 \\
\% Passing 2017-2018 ISTEP* & NA & 13 & 19 \\
\hline
\end{tabular}

Source: Indiana Department of Education.

*ISTEP, Indiana Statewide Testing for Educational Progress.

aligned with the Coalition for Community Schools' Logic Model Framework (CCS, 2007). This framework is centered on achieving results in FSCSs through a logical set of inputs and outputs based on desired short- and long-term results. The comprehensive partnership plan centered on addressing the needs of students and families at the three schools in Martindale-Brightwood, Fannie Lou Hamer (FLH), Victoria Woodhull (VW), and Alice Paul (AP), which combined serve approximately 1,300 students.

In contrast to the process in Near-Westside led by the Mary Rigg Neighborhood Center, MBAES used a fluid, open FSCS implementation process. Its vision focused on long-term goals and outcomes and sustained commitments from community leaders who envisioned the project long before its inauguration. MBAES has connected multiple agencies and community partners to provide a range of services both on and off the FSCS sites. The services include early childhood education, remedial education, and academic enrichment, parent engagement and family literacy, mentoring and youth development programs, community service and service learning opportunities, nutrition services, primary health and dental services, mental health services, job training and career counseling services, social service programs and programs that promote family financial stability, and adult education and ESL instruction. The funding from the grant also allowed for professional development support for school leaders and teachers at the three community schools. The mission of MBAES is "to advance the continuous development of a community-wide partnership between the schools, families, health and human service agencies, faithbased organizations, businesses, and colleges/universities, maximizing the education and life potential of every child, young person and adult -from cradle to career". Its primary objective is to help remedy service gaps for students and families by addressing the challenges of alignment, integration, and sustainability of resources.

MBAES has maintained consistent leadership since its inception in 2010, which has contributed to the stability and sustainability of the FSCS strategy. Despite school and district personnel and policy changes, MBAES has provided a strong backbone and aided in creating a shared sense of purpose in serving students, families, and community members. Communication, relationship building, and opportunities for authentic engagement among the collective body of partners have helped to maintain the initiative, and will help to ensure the long-term success of FSCSs in Martindale-Brightwood. 


\section{Theoretical framework}

The theoretical framework for this case study centers on Bryk et al.,'s (2010) model for organizing schools. According to Bryk et al. (2010), effective and improving schools have five essential supports, which he describes as:

1. Coherent instructional guidance systems. Schools in which student learning improves have coherent instructional guidance systems that articulate the what and how of instruction.

2. Professional capacity. Schooling is a human resource-intensive enterprise. Schools are only as good as the quality of faculty, the professional development that supports their learning, and the faculty's capacity to work together to improve instruction.

3. Strong parent-community-school ties. The quality of these ties links directly to students' motivation and school participation and can provide a critical resource for classrooms.

4. Student-centered learning climate. All adults in a school community forge a climate that enables students to think of themselves as learners. At a minimum, improving schools establish a safe and orderly environment - the most basic prerequisite for learning.

5. Leadership drives change. Principals in improving schools engage in a dynamic interplay of instructional and inclusive-facilitative leadership (p. 24-25).

Our interest in using Bryk et al.,'s (2010) model for this case study is based on extensive analysis of the qualitative data including in-depth interviews with school principals and teachers, community partners, observations of local community school council meetings, and literature written about the community school initiative. Bryk et al.,'s (2010) theoretical ideas helped to elucidate how the community school reform efforts developed over time. We deliberately decided to include two neighborhoods, not to compare their efforts of development, but instead to focus on the structures and principles that framed their work, understanding that Bryk et al.,'s (2010) five essential supports in K-12 schools may vary among the different types of school and community contexts.

To frame our study, we also focused on the four pillars that correspond to the characteristics of high-quality FSCSs: 1) integrated support services in the school, 2) expanded learning time and opportunities, 3) family and community engagement, and 4) collaborative leadership and practice (Oakes, Maier, \& Daniel, 2017). These four pillars, supported by decades of research, identify school characteristics that foster students' intellectual, social, emotional, and physical development and align with evidence-based features that define good schools. In fact, their focus on climate, leadership, and partnerships overlap with Bryk et al.s' essential supports for effective and improving schools (Bryk et al., 2010). It is through these complementary frameworks that we analyzed data derived from ten years of FSCS implementation in the Near-Westside and Martindale-Brightwood communities in Indianapolis. 


\section{Research methods}

Our research team consisted of a university professor, a doctoral graduate assistant, and the Director of University/Community School Partnerships. Different from a traditional method of inquiry, we obtained our data using a participatory action research approach (Fals-Borda \& Rahman, 1991; Stringer, 2007). This type of research aims to facilitate understanding of essential community problems and the actions necessary to solve them. It involves community participation, and fosters community ownership throughout the entire research project, particularly from those directly impacted by the problem. Along with the participant researcher, community leaders develop the capacity to take action aimed at changing community conditions and systems so that a supportive environment in schools and communities exists to sustain behavior changes over time (Stringer, 2007). This approach to research can be used to pursue research objectives (knowledge and understanding) with the meaningful involvement of community members and an ultimate focus on activities leading to improvements in social conditions (Auspos \& Kubisch, 2004).

\section{Data collection}

Data were collected during three different grant periods - 2008-2013, 2010-2015, 2015-present - from the eight focal schools in Near-Westside and MartindaleBrightwood. Much of the data for this research was gathered from participants attending monthly Community Advisory Council (Council) meetings at each of the FSCSs. The Council is a representative group of essential partners that collaborate to achieve community school goals and ensure genuine and active community engagement. The Council can include representatives from community agencies such as health care providers/agencies, public health agencies, social services agencies; community leaders; business leaders; the faith community; advocacy groups; teachers; parents; students; and the broader community. Anyone who attends the monthly meetings receives professional development on community schools and is invited to help address specific community school needs. As participant researchers, we presented evaluation data at the Council meetings and gathered responses to prompts that allowed us to more thoroughly examine challenges and successes at the FSCSs. When analyzing these data, we reviewed summaries of small group discussions, and read meeting minutes and agendas.

Over the course of the grant periods, additional data were gathered from semi-structured interviews with FSCS principals. Further, teachers were invited to an annual Teacher Appreciation Luncheon where we conducted small focus groups using nonstructured questions to learn about their concerns with the community school process, service access, and program gaps. Teachers also described what they thought were successes and challenges related to community school programs at their schools. Every semester, the teachers also completed an open-ended ten-question survey to measure their knowledge, beliefs, and relationships to community school activities.

Across the eight FSCSs in Near-Westside and Martindale-Brightwood, we learned about the effectiveness of the community schools model. We focused specifically on governance, program infrastructure, and community partnerships, which are necessary to realize essential benefits for the schools, students, and families involved in the FSCS 
initiative. Additional data sources for the study were grant performance reports and school-level statistics (e.g., overall standardized test performance).

\section{Data analysis}

In analyzing and synthesizing all the data, we used an iterative and inductive team approach (Olesen, Droes, Hatton, Chico, \& Schatzman, 1994). Through regular research meetings, we discussed our perceptions of the data as we looked for common recurring concepts and themes. As we reviewed the emergent themes and our theoretical frameworks, we identified examples of what were characterized as good practices, significant program achievements, and factors facilitating and inhibiting collaboration and sense of community within the schools and partnerships. The results were then discussed with key community members who were involved in the study. Through these discussions, consensus was built around the key findings and lessons learned. In the next section, we discuss these findings. In particular, we discuss the challenges and achievements experienced in over a decade of planning and implementing a comprehensive community school strategy in two communities in Indianapolis.

\section{Findings: Challenges and significant achievements}

Evidence from a range of community perspectives, voices, and performance data show that the challenges faced by urban community schools are continuous as systems and policies are continually changing. Despite such changes, the two focal communities have implemented community school models to strengthen teaching and learning by building on community assets and collaborative opportunities. In doing so, they have experienced challenges as well as significant achievements and benefits.

\section{Challenges}

Perhaps like other community schools in the nation, the community schools initiatives in IPS experienced significant challenges, primarily related to budget constraints and personnel turnover, and the effects of student poverty and trauma. While these challenges were commonly experienced, the intensity and response differed by school and community as described below.

\section{Budget constraints and personnel turnover}

Over the years, IPS has been closing schools because of a shrinking student body. Facing a $\$ 45$ million deficit, the district plans to close an additional three high schools. While the full impact of the closures is not yet known, media have reported that 26 teachers will lose positions and elementary schools across the district must reconfigure their grade levels by adding middle school grades to their buildings (McCoy, 2018). This change will require IPS FSCSs to identify and deliver additional services for preadolescent students including tutoring and mentoring. 
Principal and teacher turnover have also affected multiple schools serving poor students and students of color, including the FSCSs in IPS. The negative consequences of personnel turnover were recognized by one principal, who commented:

One challenge has been the constant turnover. You know, teachers could get really involved, but then that's taking away from them learning how to teach. A lot of the staff that I've had are struggling with just learning how to do their basic job duty.

Rather than trying to stem the tide of attrition from the neediest schools, the IPS approach has been to replace administrators and teachers in these often lower performing schools. In Martindale-Brightwood, for example, during the five-year FSCS grant period, VW Elementary had a new principal every year, and $60 \%$ of the teaching staff turned over every year as well. At FLH Elementary, there was a consistent principal during the five-year period, but about half of the teachers were new every year.

In Near-Westside, there is a new principal at ZNH Elementary who began her tenure during the 2017-2018 school year. A new principal took the helm of Jefferson High for the 2018-19 school year, and many of the preexisting staff relocated or retired as he selected new staff. Meanwhile, a new principal was designated for JS Elementary, and the previous leadership team moved to a technical high school on the city's NearEastside. After much debate by the IPS board and community, the school district determined that MG Elementary would convert to an "innovation network" or charter school due to multiple years of underperformance. The school opened in August 2018 under contracted management, and with a new principal and nearly all new teachers. ${ }^{1}$

The churn in school personnel has had an impact that is deep and wide. It has generated fractured relationships with students, contributing to trauma that they may experience in other areas of their lives. The loss has also diminished organizational memory, which is important to the school community. We also found that the turnover has negatively affected the development of trust between school leaders and the community, limiting the number of partners allowed in schools. At one school, the lack of trust extended to a community partner working on the FSCS grant. The partner was never invited to be a part of the school leadership team, thus causing a rift that stymied development of a trusting relationship between the partners, school personnel, and parents. Despite the turnover, the FSCS initiatives in Near-Westside and Martindale-Brightwood have continued to provide services and supports to meet students' academic, social and emotional needs.

\section{Student poverty and trauma}

For many years, poverty has affected students and families in the school district. Many students who attend IPS live in struggling communities where disadvantaged socioeconomic backgrounds make academic success highly elusive. According to the 2017 "Public Good Index" published by the Sagamore Institute, an Indianapolis think tank, the portion of Indianapolis residents living in poverty increased from $11.8 \%$ in 2000 to $21.3 \%$ in 2015 . This increase of 85,063 individuals brings the total impoverished population in Indianapolis to 175,623 (Riggs et al., 2017).

\footnotetext{
${ }^{1}$ Because of the school's new status, student data are not reported in Table 2.
} 
Recent studies indicate that many children living in poverty experience continuous trauma in their lives, including exposure to violent crimes (Kiser et al., 2010; Kiser et al., 2008; Kiser \& Black, 2005). The research also suggests that exposure to violence on the streets and in schools serves as a distraction to learning (Sitler, 2009). Thus, despite existing programs, the need for additional social and mental health services continues to be imperative in both of the focal neighborhoods. As one teacher noted, "This school benefits from the partnerships but we need more to meet the needs that we have in this school. Poverty is a big factor." A principal concurred, emphasizing the overlap between poverty, trauma, and student behavior, "Our number one [challenge] is trauma... how to address the needs of our children and families given the incredible amount of trauma that they have been through. Of course, a side effect of that trauma being the mental health issues that we see."

Several schools have adopted trauma-responsive care resources and professional development for teachers and staff so that they gain a deeper understanding of how trauma affects child development and what interventions are necessary to help children heal. A newly developed health coalition born out of the Near-Westside FSCS initiative has been instrumental in advocating for changes in school and service system policies and protocols to support trauma-affected children.

\section{Significant benefits and achievements}

While challenges exist, there is no doubt that the community school initiative has created a higher value for education that continues to permeate in Near-Westside and Martindale-Brightwood. When describing the initiative's impact, one principal observed:

As the instructional leader, I have found that I must think about all tenets of students, families, and the community. The FSCS model has forced me to do this. Our school team is learning how to become more and more aware of the varying needs of our students. This includes trauma, mental health, academic support, and social support.

When the Quality of Life Plans ${ }^{2}$ were developed by community residents in conjunction with the Local Initiatives Support Coalition of Indianapolis (LISC), both neighborhoods identified education as a top priority and the call for quality schooling is at the top of their agenda (LISC, 2019). Thus, we know the strategy has made an impact. We discuss additional benefits of the community schools model below.

\section{Outcomes at Jefferson High}

At Jefferson High, student attendance increased from $88 \%$ in 2006 to $94 \%$ in 2009 . This increase was in part due to the efforts of an interdisciplinary case management team, consisting of a social worker, a school nurse, an athletic coach, and teachers, who worked at addressing chronic absenteeism. The director of the afterschool program stated that students' desire to participate in the afterschool activities made available through the FSCS grant - called the Hub - also helped increase student attendance. The Hub provided an extended day with enrichment activities such as swimming and other athletics, recreation, college prep activities, and a hot meal every evening. Sixty

${ }^{2}$ Quality of Life Plans outline communities' definitions of ideal living conditions. 
percent of the entire student body enrolled in the Hub and attended regularly. Also, at Jefferson High, the percentage of students graduating within four years increased from $42 \%$ in 2007 to $77 \%$ in 2011. In 2009, 100\% of the high school's graduates were accepted into post-secondary educational programs. The increase in high school graduation rates resulted in more students graduating from college, a community-wide goal.

The FSCS model also benefitted the broader school community. For example, 422 area adults participated in Jefferson High's evening personal fitness program, managed by IUPUI physical education majors. Of particular significance to this school is the fact that the operation of all FSCS programing continued for three years beyond the end of the grant cycle (2011-2015), demonstrating how committed partnerships can serve as the linchpin to sustainability, despite the lack of government funding and sizeable administrative churn.

\section{Outcomes in Martindale-Brightwood}

With MBAES, the Siemer Student Stability Project, housed by project partner, Edna Martin Christian Center, was designed to support families at high risk of mobility. This program helps to prevent absenteeism and promote consistency in learning. Edna Martin Christian Center is one of 30 total partners supporting grant initiatives such as mental health, adult career development, and job training, mentoring and youth development, and health, nutrition, and wellness in Martindale-Brightwood. IUPUI Adult Learning Centers, another active partner in the MBAES program, offers courses and workshops for parents and students in Martindale-Brightwood churches and community centers - drawing in over 95 students. Several Spanish-speaking parents have enrolled in English classes, enabling them to take on school leadership roles. The Center also initiated a program titled 'Girl Talk' that gave $6^{\text {th }}$-grade girls a safe space to express themselves and learn about issues relevant to their lives. The program forged multiple oneon-one relationships between girls and mentors as the girls developed personal and social skills and critical ways to communicate effectively and feel validated.

\section{IUPUI-community school partnerships}

We must also highlight the transformative relationship established between IUPUI, the schools, and community residents. IUPUI and school representatives have routinely participated in neighborhood improvement efforts. IUPUI also has supported the schools by sending students and staff members from several departments across the campus to participate in education support services including tutoring, mentoring, afterschool activities, and management of the wellness center at the high school, which provides personal trainers and individual health assessments. In 2015, the IUPUI Office of Community Engagement made a firm commitment to this work and hired Jim Grim of the Near-Westside FSCS project to be Director of University/Community School Partnerships in their Office of Family, School and Neighborhood Engagement.

\section{Community and family engagement}

Community partner, Mary Rigg Neighborhood Center, has continued full engagement as a lead partner along with more than 70 community partners in Near-Westside that 
have collaborated to provide up to $98 \%$ of all the students who attend a FSCS with at least one supportive service. When describing the broad support provided by one school partner, a principal shared:

We have Kroger's support with scholarships. Our kids in grades 1-8 are able to get $\$ 500$ scholarships each semester that they have good attendance and grades. That's called our Kroger Super Scholars. They also provide shoes and socks for all our kids around the holidays. They give us a big feast around Thanksgiving. And each classroom has a relationship with a specific store.

While funding from the U.S. Department of Education offers support to families and community members in Near-Westside and Martindale-Brightwood, anchor-partner community centers - Christamore House, Hawthorne Community Center, Mary Rigg Neighborhood Center, and Edna Martin Christian Center - collectively provide employment, social services, preschool/childcare, afterschool activities, adult learning, and related supports for more than 14,000 families in both communities. Community partners have thus played a central and sustaining role in community school initiatives in Indianapolis.

Bringing about a system of change in the focal neighborhoods was complicated, but not overwhelming as the partners and school leaders began to understand the significance of adhering to the community school model. In monthly Council meetings, partners aligned resources with students' academic and social developmental needs. Key to the process at Jefferson High was the work of the community school coordinator (CSC), who helped to manage community outreach. When describing the importance of the CSC, the principal observed, “They are a part of our team ... it's great. They join our team meetings, and they allow us to touch students in a much more thorough way than we would be able to otherwise."

Another key factor explaining the successful implementation of the community school model was the increase in participation from parents and families, despite what one teacher described as their previously "negative experiences with schools." In 2011, parent engagement increased $100 \%$ over the previous year as nearly 1,012 family members participated in FSCS activities that were not sports-related. In other words, parents who participated in family nights, recognition programs, student-driven activities, family literacy, and Parent in Touch events helped create a school climate that was welcoming, and conducive to student learning and authentic community engagement.

FSCSs continue to work with their community partners to increase parent participation and address barriers to families' engagement. As one principal described:

We still struggle with getting our parents in. It's so dependent on time of year, time of day, because I know a lot of our parents are working, so shifts are a challenge, first shift, second shift, third shift. Child care, transportation, those are all issues. So we've been trying to make connections with our community partners to provide transportation to get parents here if they want that. We've since seen some increases in our parental involvement throughout the last couple years on events. Sometimes we'll get 10 to 15 parents, others we'll get 30, 40, 50, um, up to 200, it just depends on what we're trying to do.

Partnerships and adherence to the principles of the community school model deepened as the inclusiveness of the Councils grew. Council members learned more about the school needs and their capacity to individually and collectively approach issues that influenced the infrastructure of the school and community. Council members also 
publicly made their ideas known as they addressed the policies and actions of the school board in regards to school closings, school leadership changes, school funding, and shifts in student enrollment.

\section{Discussion: Key lessons learned}

Over a ten-year period of achievements, trials, and attempts at coordinating and aligning the moving pieces of multiple community schools, several lessons have emerged. We discuss these lessons, which we titled, "The Seven C's," within the context of existing research and theory on FSCSs and school reform. These lessons are not mutually exclusive, but rather, are complementary and reinforcing.

Lesson One - Change is the only constant. Throughout our decade of work within the district, we have learned that the need to be flexible and responsive to change is paramount. We have experienced significant transformation in the face of extensive "churn" of administrators and teachers that directly affected relationships and trust (Finnigan \& Daly, 2017), the district's modifications of practices and policies with little to no notice, and student mobility due to various economic factors (Columbus Foundation, 2003). While change is a constant and potentially disruptive, it also provides the opportunity to remain flexible and open to feedback regarding processes and approaches. Collectively, we sought stability and searched for predictability in maintaining the initiative. The achievements and benefits came with hard work and commitment to uphold the fundamental pillars of FSCSs (Oakes Maier, \& Daniels, 2017) despite the changing leadership and district messages that challenged us.

Lesson Two - Collaboration is necessary for collective impact. Bryk et al. (2010) emphasizes the importance of strong parent, community, school ties for improving schools. Our work supports this claim. We found that FSCSs do not work without the community. The community must be involved to make possible the two-way collaboration that is an essential feature of FSCSs. The successful operation of FSCSs depends on the quality and integration of the many moving parts that propel the mission. School and community leaders must abandon their personal agendas in favor of a collective approach to improving student achievement. No single influential, innovative, or resourceful organization could advance the critical needs of a community alone. Therefore, the contributions from community partnerships must be meticulously considered using a structured process that unvaryingly measures clear goals (Kania \& Kramer, 2011). FSCSs in the local communities have been sustained by a network of multiple partners, including three local community centers, a nearby university, community-based organizations and members of the private sector, who work together to improve student achievement through "collective impact." Kania \& Kramer (2011) define collective impact as a longterm commitment by a cooperative of people who come from different sectors, with a common agenda, to solve a specific social problem.

Lesson Three - Consistency and stability between organizers and partners help to sustain integrated services. Integrated services, responsive to the needs of students and families, is a defining feature of FSCSs (Oakes, Maier, \& Daniel, 2017). Educational change in our district demonstrates the need to counterbalance the churn by offering students stability and consistency in these services. For example, if a food pantry or afterschool 
program or service is open to families in year one, we work to ensure access to those resources for families in the following years through partner commitments. The longterm sustainability of programs is achieved through a strategic focus on the benefits to students and families, and "blending" and "braiding" funds to support the total cost of services (Flynn \& Hayes, 2003). Services and expenses are tracked by a categorical funding source so that each is charged its fair amount and the program data reflect both duplicated and unduplicated services provided by each program partner. The goal of this funding strategy is to develop a program infrastructure that will continue to function after the grant funding cycle ends. Although the school may see changes in administrators, the partners essentially remain constant.

Lesson Four - Communication is the foundation of a robust FSCS. Effective communication is essential to maintaining strong community school partnerships. Keeping multiple partners engaged and knowledgeable about schools' efforts and successes requires constant, precise, and robust communication at various levels. Organizing events, integrating services, and communicating the availability of services to parents and the broader community also require a great deal of effort. Thus, communication among school leaders and staff (i.e., the principal, CSC, and parent liaison) is vital to effective communication with students, teachers, parents, and partners, and the development of schools as learning communities (Schussler, 2003). We recognize that several barriers hinder good communication at various levels including the cultural and language incongruence among schools, parents, and community members (Nieto \& Bode, 2008; Sanders, 2009). We learned from our bilingual parent liaisons that timely and effective communication with parents and students who are English learners is indispensable in creating strong school-home-community partnerships. We also learned from our CSCs that in some cases, communication on paper is strongly preferred to that of technology. Both strategies have become priorities in our FSCSs.

Lesson Five - Climate and culture are significant to learning. The terms "school culture" and "school climate" both describe the interactive aspects of the school community environments that affect students, teachers, and the community. School culture is the shared values, beliefs, and behaviors that characterize the school and the classroom (Marshall, State University Center for School Safety, 2004). School climate is defined as, "[The] quality and character of school life ... and reflects norms, goals, values, interpersonal relationships, teaching and learning practices, and organizational structures" (Cohen, et al., 2009, p.182). Highly interactive, school culture and climate can influence school/parent relationships, school attendance, academic achievement, and high school graduation rates (Freiberg, 1998). Bryk et al. (2010) also describes the importance of a student-centered climate for effective and improving schools. We acknowledge that we must consider both school climates and cultures to continue our community school planning, evaluation, and active program development. We have learned about the range of ways that we can improve both the school climate and culture by listening, planning, and taking action at the school level.

Lesson Six - CSCs are necessary to align the school's academic achievement goals and the needs of students and their families. Full-time CSCs are essential to the effective implementation of FSCSs, and need support and continuous professional development to be able to orchestrate the services and programs that are a central pillar of these schools 
(FitzGerald \& Quiñones, 2018; Sanders, 2016; Sanders, Galindo, \& DeTablan, 2019). Meaningful professional development would assist CSCs to collaborate effectively with multiple stakeholders, participate in school decision making, and develop trust with the principal and key partners, which is a hallmark of effective and improving schools (Bryk et al., 2010). Beyond family engagement, community engagement, and youth development, we depend on CSCs to help with data collection and assessment. The challenge in this school district has been the constant change in CSCs or elimination of the position, thus creating a gap in communication and authentically aligned program development.

Lesson Seven - Without principals' consent and fidelity to the model, FSCSs will not succeed. Our work, like Bryk et al.,'s (2010) and others (Adams \& Jean-Marie, 2011; Sanders, 2018;

Valli, Stefanski, \& Jacobson (2018), confirms the critical role of principal leadership for reform coherence, building professional capacity, and managing change. The three principals involved at the onset of the FSCS effort embraced the model and recognized its value to families and students. The challenge emerged when new principals assumed they knew the mechanics of community schools but in reality did not fully comprehend the foundational tenants. This created gaps in the provision of services and programs when the principal decided too many "outsiders" were involved in school decisions and limited the number of providers in the building.

\section{Conclusion}

The community leaders who envisioned FSCSs long before the inauguration of the 2000 reopening of Jefferson High, shared their hope and a sense of urgency when they committed to this promising school reform movement. Through collective partnerships and distributive leadership among the school district, university, and community-based organizations, they embraced the standards for quality education, championed authentic community engagement, and intentionally integrated teachers and public/private partnerships as the foundation for academic success. While the initial FSCS grants provided essential funding and strengthened the capacity of the school and community, discovering and maintaining the resources and assets for over ten years, in part, is due to the steadfast efforts of IUPUI and community organizations such as Mary Rigg Neighborhood Center and MBAES. They worked to sustain program funding beyond the contracted grant periods through continuous technical assistance and capacity building, and captured the data to document the evidence needed to renew programs. This vibrant example of scholars working alongside practitioners in assessing program standards, questioning vexing contradictions, and addressing the pestilence of bias in public schools in poor communities is what makes this project unique and a model for other urban districts.

\section{Funding}

Office of Innovation and Improvement.

\section{References}

Adams, C. M., \& Jean-Marie, G. (2011). A diffusion approach to study leadership reform. Journal of Educational Administration, 49(4), 354-377. doi:10.1108/09578231111146452 
Auspos, P., \& Kubisch, A. C. (2004). Building knowledge about community change: Moving beyond evaluations. New York, NY: Aspen Institute. doi:10.4087/FOUNDATIONREVIEW-D$11-00010$

Blank, M. J., Melville, A., \& Shah, B. P. (2003). Making the difference: Research and practice in community schools. Washington, DC: Coalition for Community Schools. Retrieved from www. communityschools.org/CCSFullReport.pdf.

Brooks-Gunn, J., \& Duncan, G. (1997). The effects of poverty on children. The future of children. Center for the Future of Children, the David and Lucile Packard Foundation, 7, 55-71. doi: $10.2307 / 1602387$

Bryk, A. S., Sebring, P. B., Allensworth, E., Luppescu, S., \& Easton, J. Q. (2010). Organizing schools for improvement: Lessons from Chicago. Chicago, IL: University of Chicago Press

Catalog of Federal Domestic Assistance (CFDA). (2018). number 84.215J. June 13). Applications for New Awards; Full-Service Community Schools Program, 27564-27570. Retrieved from: https://www.federalregister.gov/d/2018-12701.

Cohen, J., McCabe, E. M., Michelli, N. M., \& Pickeral, T. (2009). School climate: Research, policy, practice, and teacher education. Teachers College Record, 111, 180-213.

Columbus Foundation. (2003). Columbus public schools student mobility project report. Columbus, $\mathrm{OH}$ : The Columbus Foundation Community Research Partners.

Darling-Hammond, L. (2006). Constructing 21st-Century Teacher Education. Journal of Teacher Education, 57(3), 300-314. doi:10.1177/0022487105285962

Davila, K., Nowlin, M., \& Andres, M. A. (2018). Where Schools Are Changing: Regional and Neighborhood Dynamics from 2010 to 2016. Retrieved from The Polis Center Indiana University Purdue University at Indianapolis website: http://polis.iupui.edu/wp-content/ uploads/2018/12/Where-Are-Schools-Changing.pdf

Fals-Borda, O. \& Rahman, M. A. (Eds.). (1991). Action and knowledge: Breaking the monopoly with participatory action research. New York: Apex Press.

Finnigan, K. S., \& Daly, A. J. (2017). The trust gap: Understanding the effects of leadership churn in school districts. American Educator, 41(2), 24-43.

FitzGerald, A. M., \& Quiñones, S. (2018). The community school coordinator: leader and professional capital builder. Journal of Professional Capital and Community, 3(4), 272-286. doi: 10.1108/JPCC-02-2018-0008

Flynn, M., \& Hayes, C. D. (2003). Blending and braiding funds to support early care and childhood initiatives. Washington, DC: The Finance Project.

Freiberg, H. J. (1998). Measuring school climate: Let me count the ways. Educational Leadership, 56(1), 22-26.

Galindo, C., Sanders, M., \& Abel, Y. (2017). Transforming educational experiences in low-income communities: A qualitative case study of social capital in a full-service community school. American Educational Research Journal, 54(1_suppl), 140S-163S. doi:10.3102/000283121 6676571

Grim, J., Medina, M. A., \& Officer, S. D. H. (2011). A Decade of Lessons: Community Engagement Perspectives from a University-Assisted School Community. Midwest Center for University-Assisted Community Schools, Center for Service and Learning, Indiana University Purdue University Indianapolis.

Kania, J., \& Kramer, M. (2011). Collective Impact. Stanford Social Innovation Review, 9(1), 36-41.

Kiser, L. J., \& Black, M. A. (2005). Family processes in the midst of urban poverty. Aggression and Violent Behavior, 10(6), 715-750. doi:10.1016/j.avb.2005.02.003

Kiser, L. J., Medoff, D. R., \& Black, M. M. (2010). The role of family processes in childhood traumatic stress reactions for youths living in urban poverty. Traumatology, 16(2), 33-42. doi: $10.1177 / 1534765609358466$

Kiser, L. J., Nurse, W., Lucksted, A., \& Collins, K. S. (2008). Understanding the impact of trauma on family life from the viewpoint of female caregivers living in urban poverty. Traumatology, 14(3), 77-90. doi:10.1177/1534765608320329 
Local Initiative Support Council. (2019). Six Quality-of-Life Plans for Indianapolis Neighborhoods. Retrieved from: http://archive.instituteccd.org/-How-To-Do-It-/Planning/Six-Quality-of-LifePlans-for-Indianapolis-Neighborhoods0.html

Lubell, E. (2011). Building Community Schools: A Guide for Action; Children's Aid Society: New York, NY, USA.

Marshall, M. L, State University Center for School Safety. (2004). Examining School Climate: Defining Factors and Educational Influences [white paper, electronic version]. Retrieved from Georgia, School Climate, and Classroom Management website: http://education.gsu.edu/ schoolsafety/

McCoy, D. (2018). Indianapolis Public Schools cancels contracts for 26 educators, 46 other staffers amid financial problems Chalkbeat. Retrieved from: https://chalkbeat.org/posts/in/2018/ 06/29/indianapolis-public-schools-cancels-contracts-for-26-educators-46-other-staffers-amidfinancial-problems/

Nieto, S., \& Bode, P. (2008). Affirming diversity: The sociopolitical context of multicultural education. Boston, MA: Pearson/Allyn and Bacon.

Oakes, J., Maier, A., \& Daniel, J. (2017). Community schools: An evidence-based strategy for equitable school improvement. Palo Alto, CA: Learning Policy Institute.

Olesen, V., Droes, N., Hatton, D., Chico, N., \& Schatzman, L. (1994). Analyzing together: Recollections of a team approach. Dans A. Bryman, \& R. G. Burgess (Eds), Analyzing qualitative data (pp. 111-128). London: Routledge.

Riggs, T., Batson, C., Curry, K., Dewes, E., Heikens, N., Clark, K., \& Nepomuceno, B. (2017). Public Good Index at Sagamore Institute: A Study of Indiana's Major Cities. Retrieved From: http://www.avongov.org/egov/documents/1515770622_51989.pdf.

Sanders, M. G. (2009). Teachers and Parents. In L. Saha \& A. Dworkin (Ed.), The New International Handbook of Teachers and Teaching. (pp. 331-343). New York, NY: Springer, Boston, MA.

Sanders, M. G. (2016). Leadership, partnerships, and organizational development: Exploring components of effectiveness in three full-service community schools. School Effectiveness and School Improvement, 27(2), 157-177. doi:10.1080/09243453.2015.1030432

Sanders, M. G. (2018). Crossing boundaries: A qualitative exploration of relational leadership in three full-service community schools. Teachers College Record, 120(4), 1-36.

Sanders, M., Galindo, C., \& DeTablan, D. (2019). Leadership for collaboration: exploring how community school coordinators advance the goals of full-service community schools. Children and Schools, 41(2), cdz006. doi:10.1093/cs/cdz006.

Schussler, D. L. (2003). Schools as learning communities: unpacking the concept. Journal of School Leadership, 13(5), 498-528.

Sitler, H. C. (2009). Teaching with awareness: The hidden effects of trauma on learning. The Clearing House: A Journal of Educational Strategies, Issues, and Ideas, 82(3), 119-124. doi: 10.3200/TCHS.82.3.119-124

Stringer, E. T. (2007). Action Research (3rd ed.). Thousand Oaks, CA: Sage Publications.

Valli, L., Stefanski, A., \& Jacobson, R. (2018). School-community partnership models: Implications for leadership. International Journal of Leadership in Education, 21(1), 31-49.

Warren, S. R. (2002). Stories from the classroom: How expectations and efficacy of diverse teachers affect the academic performance of children in poor urban schools. Educational Horizons, 80(3), 109-116.

Wirt, J., Rooney, P., Choy, S., Provasnik, S., Sen, A., \& Tobin, R. (2004). The Condition of Education 2004 (NCES 2004-077). Washington, DC: National Center for Educational Statistics, Institute of Education Sciences. Source: http://nces.ed.gov/pubsearch/pubsinfo.asp?pubid $=2004077$. 